\title{
LEFT ATRIAL APPENDAGE MANAGEMENT: A SURGICAL PERSPECTIVE
}

\author{
Fabrizio Rosati ${ }^{1}$, Gijs de Maat ${ }^{2}$, Massimo Mariani $^{2}$, and Stefano Benussi ${ }^{1}$ \\ ${ }^{1}$ University of Brescia \\ ${ }^{2}$ University Medical Centre Groningen
}

January 13, 2021

\begin{abstract}
Atrial fibrillation $(\mathrm{AF})$ is the most common atrial arrhythmia but it is not a benign disease. AF is an important risk factor for thromboembolic events, causing significant morbidity and mortality. The left atrial appendage (LAA) plays an important role in thrombus formation but the ideal way to manage the LAA is still debated. The increasing popularity of surgical epicardial ablation and hybrid endo-epicardial ablation approaches, especially in patients with a more advanced diseased substrate, has raised the interest in epicardial LAA management. Minimally invasive treatment options for the LAA offer a unique opportunity to close the LAA with a clip device. This review highlights morphologic, electrophysiologic and surgical aspects of the left atrial appendage with regard to atrial fibrillation surgery, and aims to illustrate the different surgical management strategies.
\end{abstract}

\section{Hosted file}

LAA management Review FINAL.pdf available at https://authorea.com/users/389313/articles/ 503940-left-atrial-appendage-management-a-surgical-perspective

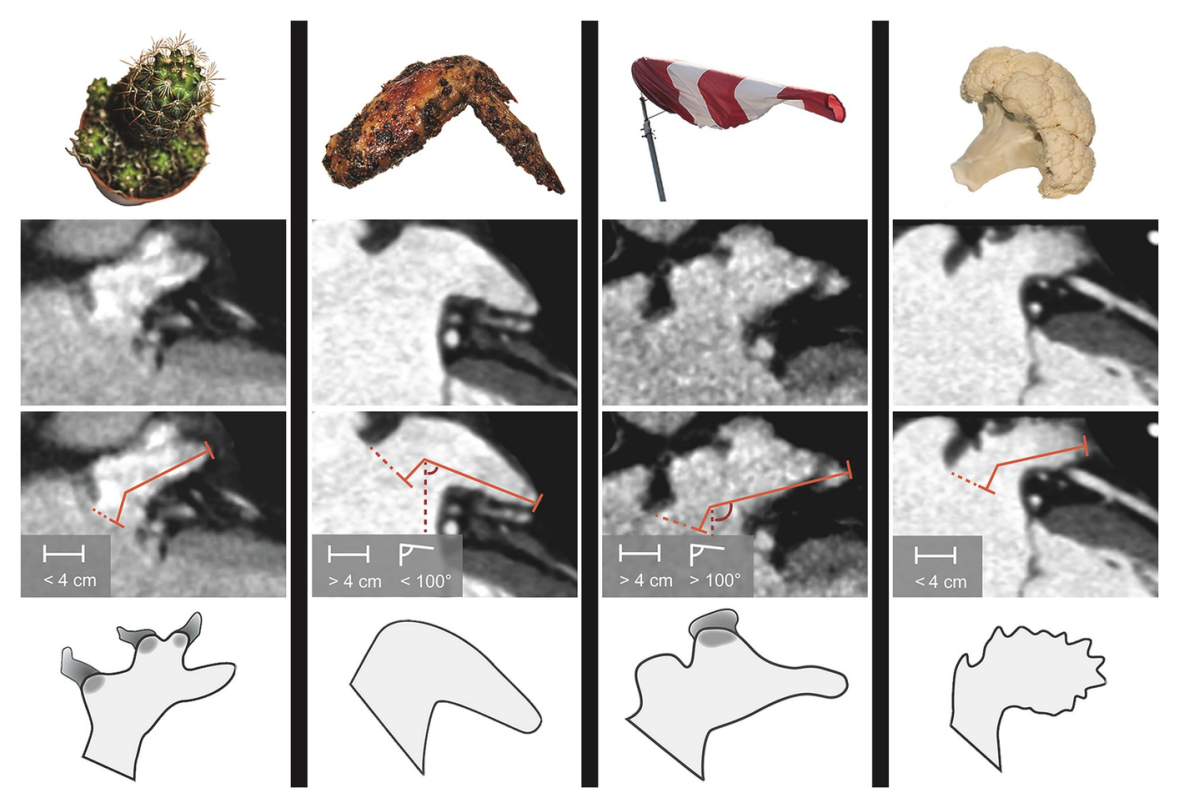



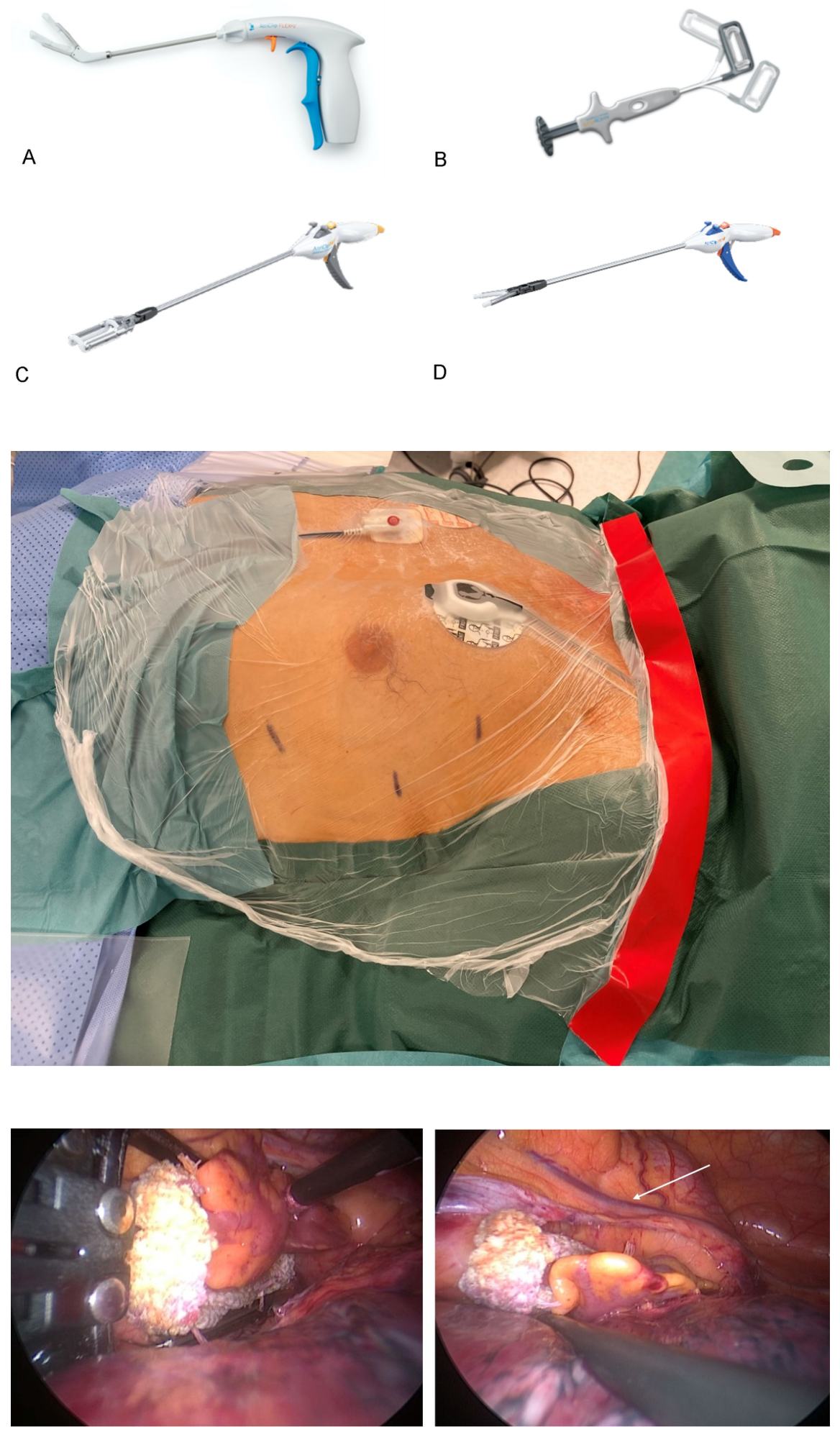

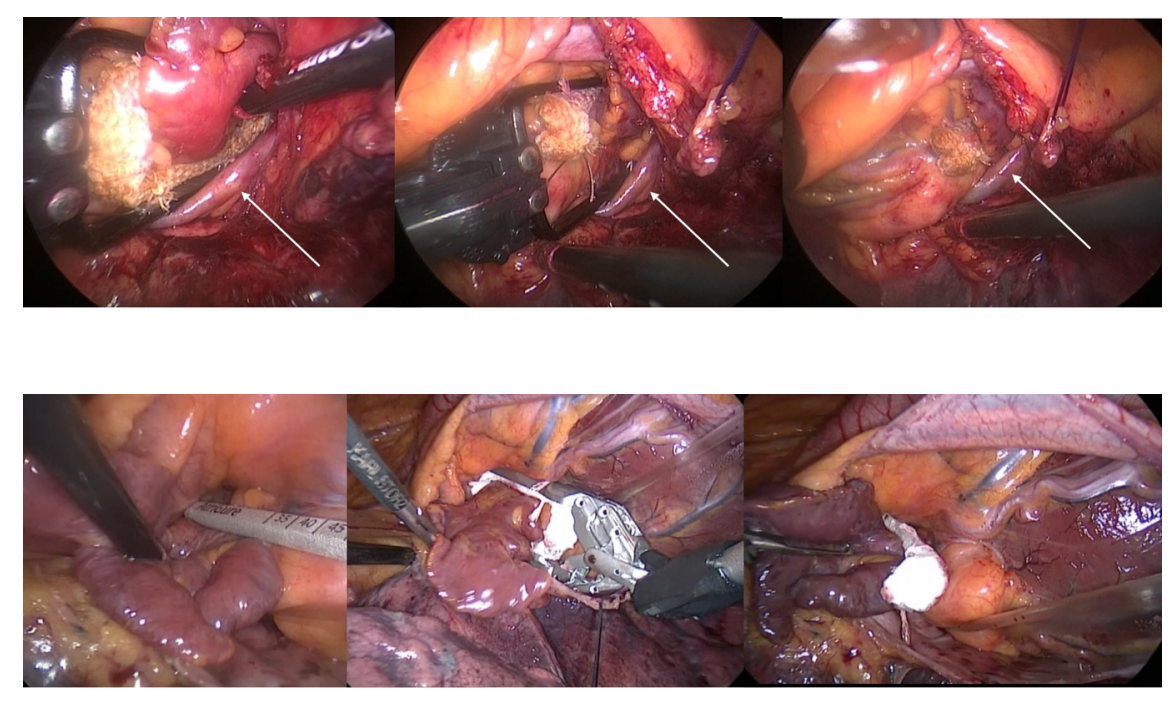